\title{
EL CONCUBINATO EN EL DERECHO INTERNACIONAL PRIVADO MEXICANO
}

\section{THE CONCUBINATE IN MEXICAN PRIVATE INTERNATIONAL LAW}

\author{
Jorge Alberto Silva ${ }^{1}$
}

Sumario: Introducción. I. Antecedentes. II. Concepto, definición y denominaciones. III Fuentes Jurídicas IV. Calificación del supuesto fáctico V. Regulación jurídica VI. Reconocimiento del concubinato constituido en el extranjero. Conclusión

\section{Resumen}

La carencia de regulación mexicana relacionada con los problemas de tráfico jurídico internacional concordados con el concubinato, hace necesario fijarse metas y establecer reglas claras que incluyan su regulación. Para eso, es necesario que nuestros legisladores se pongan a trabajar y pensar en soluciones.Aunque ciertamente es necesario tomar en cuenta diversos derechos humanos, ya reconocidos en forma general, también será necesario concretizar los datos o elementos reales a tomar en cuenta.Asimismo, es necesario comenzar enfatizando en la calificación de la situación, en la capacidad para constituir la unión, la forma (incluida la escrita y registrada), las relaciones de pareja (tomando en cuenta sus costumbres, a partir de la ley de la residencia habitual), así como los efectos de la terminación de la relación concubinaria.

En el ámbito convencional internacional es necesario contribuir para lograr un convenio sobre la materia, en el que se reconozcan los derechos, registros y efectos.

Palabras clave: concubinato, Hague Conference

\section{Abstract}

The lack of Mexican regulation related to the problems of international legal traffic agreed with the concubine, makes it necessary to set goals and establish clear rules that include their regulation. For that, it is necessary for our legislators to put themselves to work and to think about solutions. Although it is certainly necessary to take into account various human rights, already

${ }^{1}$ Profesor de Derecho de los conflictos, Presidente de la Asociación Mexicana de Profesores de Derecho Internacional Privado, Investigador Nacional CONACYT, Nivel III. 
recognized in general terms, it will also be necessary to concretize the actual data or elements to be taken into account. It is also necessary to start by emphasizing the qualification of the situation, in the capacity to constitute the Union, the form (including the written and registered), the relations of couple (taking into account their customs, from the law of the habitual residence), as well as the effects of the termination of the concubine relationship. In the international conventional area, it is necessary to contribute to a convention on the subject, recognizing the rights, registries and effects.

Keywords: concubinage, Hague Conference.

\section{Introducción}

Aunque se había creído durante siglos que el matrimonio era la única forma de constituir una familia a partir de una pareja de hombre y mujer, los hechos nos han venido mostrando que una parte considerable de la familia contemporánea no surge únicamente de un matrimonio tradicional, sino de parejas no casadas. El hecho real a tomar en cuenta es que una parte de la población ha decidido dejar el matrimonio y conformar uniones de pareja (familia convivencial). Lo que en otra época fue una forma de conformar a la familia (la tradicional), casi universal, hoy en día, va en picada.

El hecho, es que la situación concubinaria raramente ha sido objeto de estudio en el Derecho Internacional Privado. Muy poco se ha expresado sobre la temática, lo que procuro abordar en estas líneas. Pretendo presentar las aportaciones generadas en el derecho internacional privado en torno al desarrollo de textos de derecho convencional internacional sobre el concubinato. Parecerá raro, pero el caso es que de hecho no ha habido nada especial, salvo interpretaciones derivadas a textos sobre derechos humanos. Se ha generado propuestas en la Conferencia de La Haya, pero solo hasta ahí, aunque parece que ya se empieza a generar un sentido favorable. En el ámbito del derecho interno, solo en algunos países existen textos legales, aunque pocos con "vocación internacional".

La temática la reduzco a los problemas de tráfico jurídico internacional en México, por lo que no es precisamente un derecho universal el que cubre estas notas. Presento, además, como elementos previos, algunas notas relacionadas con los antecedentes estadísticos del concubinato en México, con el fin de que nuestros atrasados e inexpertos legisladores puedan apreciar su importancia y la necesidad de 
legislar sobre estos temas. Adiciono un concepto que creo que ha de ser útil.

\section{Antecedentes}

En México el matrimonio ha ido a la baja. En el año 2000 se contabilizaron 707, 422 matrimonios, mientras que, en 2015 , solo $243,082 .{ }^{2}$ En el caso de uniones libres (como se le designa en INEGI) mientras en el año 2000 se registró que un 44.6 por ciento de la población se encontraba casada, solo el $10.2 \%$ estaba en unión libre. En cambio, para 2010 , el porcentaje de casados bajó a $40.7 \%$ y las uniones libres aumentaron a $14.4 \%$ del total de la población. ${ }^{3}$ Estos datos nos muestran un incremento en la tasa de concubinatos y un descenso en el de los matrimonios, llevándonos a pensar en la importancia que adquiere para el derecho este tipo de uniones.

Cabe tomar en cuenta que hasta no hace mucho tiempo el adulterio era sancionado penalmente; incluso, que no era admisible el concubinato con un casado. El hecho es que este delito no suele tipificarse y el concubinato, entre casados, suele aumentar, aunque no necesariamente es reconocido en todas partes como conducta jurídica admitida.

Tradicionalmente la familia solo fue entendida como la constituida a partir de un matrimonio. El hecho de que alguien viviese fuera del matrimonio era entendido como si viviera "fuera de familia". No obstante, hoy en día, el concepto familia no solo comprende al surgido del matrimonio, también a las parejas de hecho. ${ }^{4}$

El fenómeno ocurrido en México (al aumentar el concubinato), no es meramente local, sino que se extiende en todos los estados de la comunidad internacional.

\footnotetext{
2 INEGI Estadísticas de natalidad, mortalidad y nupcialidad.

3 INEGI. Censos de Población y Vivienda, 2000 y 2010.

${ }^{4}$ Debo hacer constar que un concepto jurídico no se corresponde con etéreas o supuestas "esencias" o ideales, sino con significados creados por una cierta comunidad jurídica. Esta, la comunidad, conforma y recrea constructos y significados, que sufren cambios al paso del tiempo y realidades. Corresponde a expresiones que designan algo. La familia es designada, con esta expresión, para comprender un significado más amplio que el tradicional. Es una expresión del habla natural de una cierta comunidad jurídica que comprende un símbolo del mundo que rodea a esa comunidad.
} 


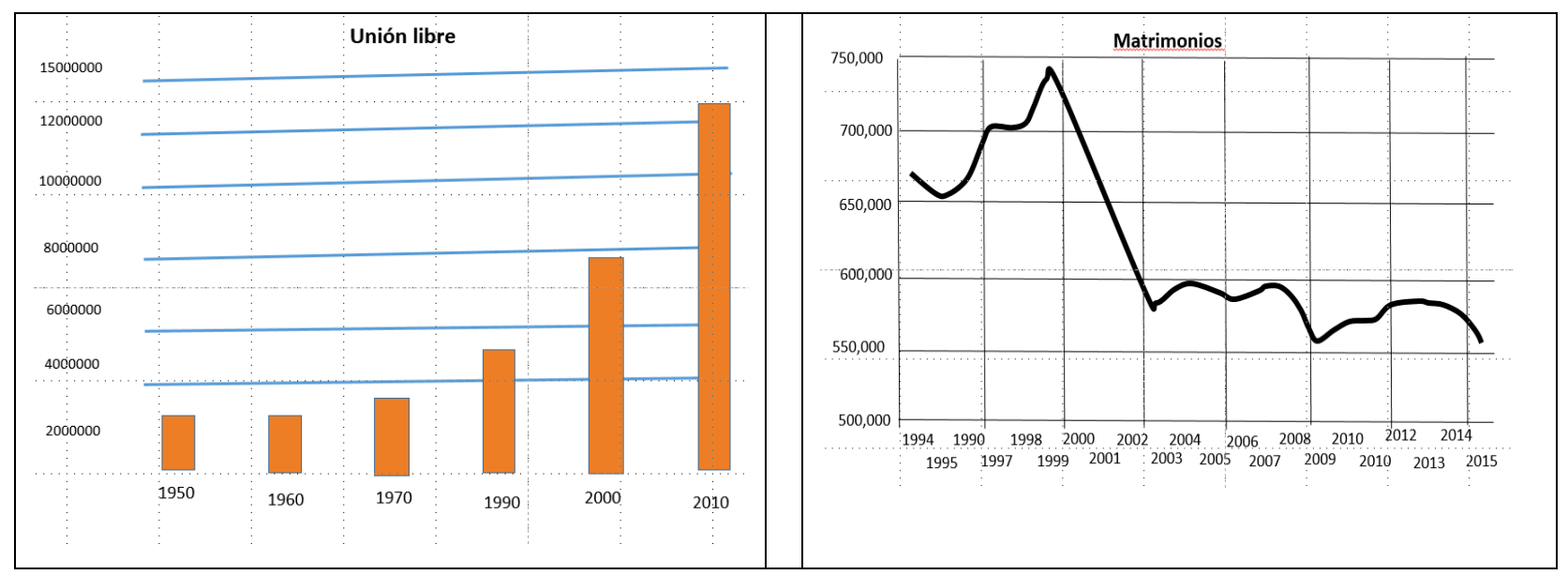

En EUA, por ejemplo, entre el año 2000 y el 2010, el concubinato aumentó en un 46\%. Ocurre algo similar en otros países europeos y sudamericanos: el concubinato o "unión matrimonial de hecho" (como algunos le han designado) ha crecido y el matrimonio ha disminuido. Se trata de un fenómeno social que necesariamente el derecho debe tomar en cuenta.

Además de lo anterior, es necesario tomar en cuenta diversas variables que han producido una migración mundial, misma que ha aumentado. En esta peregrinación y desplazamientos de concubinos, se encuentran comerciantes, que cambian de domicilio, estudiantes que se trasladan a diversos lugares, necesidades de trabajo, que llevan a las personas a otros lugares, etc. Ocurre, a la vez, que los valores familiares se han venido transformando. Esto es, que se hace necesario tomar en cuenta la problemática que el fenómeno del concubinato le presenta al derecho internacional privado, especialmente del conflictual. Por desgracia, nuestros insensibles y adormecidos legisladores no han tomado en cuenta este fenómeno.

\section{Concepto, definición y denominaciones}

Carecemos de un concepto común acerca del concubinato, como lo ha advertido la Conferencia de La Haya. Esto se debe, seguramente, a los cambios y variedades que existen en el mundo y que, obviamente, derivan de las tradiciones de cada pueblo.

Al revisar el derecho prescrito, encontramos que existen uniones que no están registradas y otras, que están registradas (son más novedosos). Las no registradas son similares a las del concubinato tradicional acogido en México; las registradas, suponen 
un previo registro y generalmente se refieren a personas del mismo sexo, aunque en algunos lugares comprenden las de ambos sexos. Por ejemplo, se suele aceptar uniones registradas entre personas de diferente sexo o del mismo sexo en la ciudad autónoma de Buenos Aires, Quebec, Holanda, Francia. Normalmente suele tratársele a las registradas y las no registradas de la misma manera.

En el mundo suele conocérsele como concubinato, matrimonio de hecho, unión de parejas estables, "pacte civil de solidarité". En la Ciudad de México tuvimos (desde 2006), "la sociedad de convivencia". Lo mismo ocurrió en Coahuila (a partir de 2007); en ambas entidades federativas se trató de una reunión civil, sin distinción de los sexos de las personas que lo conformaron. El artículo 385-I de la ley coahuilense lo definió como:

El pacto civil de solidaridad es un contrato celebrado por dos personas físicas, mayores de edad, de igual o distinto sexo, para organizar su vida en común. Quienes lo celebran se considerarán compañeros civiles. Los compañeros civiles, se deben ayuda y asistencia mutua, consideración y respeto, así como deber de gratitud recíprocos y tendrán obligación de actuar en interés común; de igual manera tendrán derecho a alimentos entre sí.

En forma sencilla, Quebec define al concubinato como una unión civil, que surge de un compromiso entre dos personas que viven en común.

Por otra parte, se hace necesario diferenciar al concubinato de lo que suele llamarse "caring relationships", que consiste en el apoyo doméstico y cuidado personal, como en Bélgica, donde se permite registrar este tipo de relaciones. No se trata de relaciones semejantes al matrimonio, ni de que legitimen relaciones sexuales, sino solo de apoyo y cuidado personal, en las que confluyen parientes entre sí, como hermanos. Así ocurre en Australia o Suecia. ${ }^{5}$

El concubinato tradicional se constituye a partir de cierto tiempo de cohabitar. En

${ }^{5}$ Galván Rivera expresa que también debe diferenciársele de la relación adulterina, la incestuosa o el amasiato. Galván Rivera, Flavio, "El concubinato actual en México", en Ensayos Jurídicos en memoria de José María Cajica, vol. I, Puebla, Cajica, 2002. Sobre caring relationships, véase Herring, Jonathan, Caring and the law, United Kingdom, Hart Publishing, 2013. 
este, el plazo, suele ser sustituido por el nacimiento de un hijo. ${ }^{6}$ Tal periodo es variable de Estado en Estado. En Asturias, por ejemplo, basta un año, dos, en Perú y Portugal, tres en Croacia, Guatemala y el Salvador o cinco, como en Jalisco, México o a partir del momento en que se celebra y registra, en el caso de los registrados.

Como quiera que sea, la unión, en cualquiera de las formas conocidas, suele ser permanente e ininterrumpida. Se le caracteriza como la unión de una persona con otra. Cuando se trata de la unión de varias, no califica en el concubinato, ni (hasta ahora) cuando concurre el matrimonio con otra persona, salvo en algunos lugares del mundo. No obstante, suelen presentarse Estados que admiten el concubinato, a pesar del número de concubinas (equivalente a la poligamia) o de que uno de los miembros esté casado.

Es posible que las variaciones se presenten en cuanto al género, pues hay concubinatos solo entre personas de diferente sexo o del mismo. Su nota principal es que la pareja vive en común, en forma permanente, como si fuese un matrimonio. ${ }^{7}$

\section{Fuentes jurídicas}

Carecemos hasta el momento de disposiciones propias de DIPr que regulen el concubinato. De ahí la importancia que le ha dado la Conferencia de La Haya al tema. Pocos y raros países se han atrevido a establecer prescripciones que regulen los problemas de tráfico jurídico internacional, pero limitándose al concubinato registrado. Gran parte de lo existente, deriva de leyes de fuente interna.

Desde hace tiempo, la Conferencia de La Haya ha procurado conformar un convenio internacional relacionado con el concubinato. Las aportaciones de la gran mayoría de países, condujo a una nota sobre el desarrollo de este apartado jurídico, en 2008 , que posteriormente fue actualizada y publicada, del cual tomo una parte. ${ }^{8}$

${ }^{6}$ En México, no basta el nacimiento del hijo, es necesaria la convivencia. Semanario Judicial de la federación, Pleno en Materia civil del primer circuito, registro: 2013735.

${ }^{7}$ En México la SCJN ha establecido que el concubinato tradicional no se reduce a personas de diferente sexo. Registro: 2012506; igualmente: 2012507.

${ }^{8}$ Se trata de las siguientes producciones: Note sur les developpements en droit interne et droit international prive sur la cohabitation hors mariage, y compris les 
El hecho es que, como lo ha puesto de manifiesto la Conferencia de La Haya, ...la ausencia de legislación nacional sobre la convivencia fuera del matrimonio o las normas de conflicto de leyes aplicables puede conducir a la situación de que ninguna autoridad sea competente para tratar cuestiones jurídicas (por ejemplo, en relación con la disolución de una pareja registrada) y dar lugar a un conflicto de jurisdicción negativo. Por otra parte, la existencia de reglas de derecho internacional privado en conflicto puede conducir a un forum shopping y a una "precipitación del tribunal". ${ }^{9}$

Al lado de esto, la reticencia de varios estados, ha llevado a las personas a buscar el foro que más les conviene para obtener un cierto reconocimiento legal, que su país no les concede, en ocasiones, con fraude a la ley. Como lo explica la Conferencia de La Haya:

Si bien algunos Estados tratan las asociaciones sobre la base de las normas adoptadas para el matrimonio, otros consideran que las asociaciones son relaciones familiares que deben estar sujetas a normas específicas. Estas normas determinan si la autoridad de un Estado es competente o no para registrar una sociedad $y$, por lo tanto, se diferencian de jurisdicción a jurisdicción. $^{10}$

Incluso, en la competencia jurisdiccional, se presenta problemas para dar por concluida la unión. Algunos de los Estados han fijado reglas propias del forum necesitatis para

partenariats enregistres, elaborado por Caroline Harnois y Juliane Hirsch (ambas collaboratrice juridique). El primero corresponde al documento preliminar núm. 11, de marzo de 2008, a la atención del Consejo de abril de 2008 sobre Asuntos Generales y Política de la Conferencia. Hague Conference on Private International Law (https://assets.hcch.net/docs/2ac5c1bc-af74-464d-9be4-cfe184eadba3.pdf).

Igualmente, el Update on the developments in internal law and private international law concerning cohabitation outside marriage, de marzo de 2005, documento preliminar, elaborado por la Oficina Permanente, núm. 5, de marzo de 2015 a la atención del Consejo sobre Asuntos Generales y Política de la Conferencia (https://assets.hcch.net/upload/wop/gap2015pd05en.pdf).

${ }_{9}^{9}$ Update on the developments in internal law and private international law concerning cohabitation outside marriage, arriba citado, número 36.

${ }^{10}$ Update on the developments in internal law and private international law concerning cohabitation outside marriage, arriba citado, número 40. 
resolver este tipo de problemas. Por ejemplo, la Ley Federal Suiza sobre Derecho Internacional Privado prescribe:

Cuando la pareja no esté domiciliada en Suiza y ninguno sea suizo, los tribunales suizos del lugar de registro tienen competencia para conocer de las acciones o peticiones relativas a la disolución de un registro a condición de que la acción o la petición no puedan presentarse en el domicilio de cualquiera de los socios o de que dicha presentación no pueda razonablemente exigirse.

En realidad, aún predomina un caos en torno al derecho regulador de estas uniones de hecho. La Conferencia de La Haya ha resumido la problemática diciendo que:

Las reglas que los Estados han adoptado para determinar la ley aplicable difieren. Algunos Estados aplican el derecho interno exclusivamente en lo que respecta a las consecuencias de la asociación registrada y, por lo tanto, tratan a las uniones extranjeras registradas como sociedades de hecho, independientemente de dónde se hayan registrado. Este método conduce a una "reescritura" de la asociación y puede conducir a que la asociación produzca menos o más efectos de los inicialmente previstos por los socios. ${ }^{11}$

En 2007 (septiembre 5) se concluyó la Convention on the recognition of registered partnerships, que aún no ha entrado en vigor. ${ }^{12}$ Fue elaborada por la Comisión Internacional sobre el Estatuto Civil, pero solo España y Portugal la ratificaron. Tiene como objetivo reconocer formas no matrimoniales y comprende uniones de pareja del mismo sexo o de diferente. Conforme a este convenio, una unión de este tipo, impide la constitución de otra, impide su reconocimiento cuando ya fue constituida en otro Estado, reconoce la disolución o anulación resuelta en otro Estado, etc.

En México, carecemos de una Ley de derecho internacional privado que prevea la regulación de este tipo de problemas de tráfico jurídico internacional. También

11 Update on the developments in internal law and private international law concerning cohabitation outside marriage, arriba citado, número 49.

12 Puede consultarse en:

https://web.archive.org/web/20120320051432/http://www.ciec1.org/Conventions/Con v32Ang.pdf, incluidas algunas explicaciones. Algunas notas adicionales sobre esta en: N. A. Baarsma, The Europeanisation of International Family Law, T.M.C. Netherlands, Asser Press, 2011, págs. 53 y ss. 
carecemos de disposiciones de fuente interna que tomen en cuenta los problemas de tráfico jurídico internacional que surjan. Pero el hecho de que carezcamos de prescripciones jurídicas especiales, ello no implica la prohibición de tales uniones, ni de que dejen de ser resueltas por nuestros tribunales. Esto último, a partir de normas generales de Derecho internacional privado, como paso a explicarlo en las próximas líneas.

\section{Calificación del supuesto fáctico}

El concubinato tradicional plantea problemas de calificación. El hecho es que con el concubinato se está reconociendo una realidad, que es la de una gran cantidad de mexicanos que viven en unión libre, y que, desde un nuevo paradigma, estimo debe calificársele como parte del estado civil de las personas.

Se trata de un fenómeno que suele presentarse en países de Centro y Sudamérica. A pesar de lo anterior, hay algunos autores que lo califican como un contrato.

En el estudio de la Conferencia de La Haya, a que me he venido refiriendo, se resaltan las posibilidades que plantea la calificación: como una cuestión de estado personal o como un contrato. ${ }^{13}$

Con un sentido más particular, en España, el profesor José Antonio Tomás Ortiz, sostiene que el concubinato no es un elemento familiar, sino una cuestión prematrimonial. Según el autor, no puede ser familiar porque no implica una familia; más bien -afirma--, se trata "de una obligación civil convencional".

A mi parecer, Tomás Ortiz desconoce que el concubinato en sí es ya una familia, por lo que considerarlo asunto prematrimonial es claramente una distorsión. En países como México difícilmente podría calificarse al concubinato como una simple "obligación civil convencional" (prácticamente un contrato), ya que la realidad nos muestra que existe un alto número de familias que conviven en relaciones surgidas de aquél; se trata necesariamente de relaciones que no sólo son convencionales, sino

${ }^{13}$ Note sur les developpements en droit interne et droit international prive sur la cohabitation hors mariage, y compris les partenariats enregistres, nota número 162, $\mathrm{p}$. 39. 
mayoritariamente de familia. ${ }^{14}$ Prueba de lo anterior, es el examen que ha venido realizando la Conferencia de La Haya, en donde sobresale el elemento familiar por sobre el contractual.

Un estudio de la antropología jurídica mexicana y de la realidad social puede conducirnos a una aceptación de esa forma de vida familiar y asimilarla al matrimonio. Como se advierte de los datos estadísticos presentados, se trata de una forma de comportamiento que han adoptado millones de parejas y que se extiende en la sociedad. Ellas constituyen familias que son una parte considerable del núcleo de la sociedad mexicana y, por tanto, su concepto debe ser calificado como un aspecto del estado civil de las personas (el significado que nuestra comunidad jurídica le atribuye, como arriba lo comenté). A ese estado convergen valores y realidades estrechamente amalgamadas a la familia, por lo que su concepto no encaja en una mera situación prematrimonial, contractual o prefamiliar, sino en la fasmiliar.

No quiero olvidar que la calificación a que me refiero se apoya en un paradigma. Esto es, todo paradigma supone un conjunto de creencias en la que convienen los científicos, en este caso, los juristas. Supone, al menos para la comunidad jurídica mexicana, una creencia que guia sus construcciones, identifica problemas y permite resolverlos; todo, apoyado en datos o hechos reales, propios de la sociedad mexicana. El concepto de familia tradicional ha caminado a la admisión de una "familia de hecho"; ya de mera convivencia o registrada, pero, al fin y al cabo, como parte de la familia.

En las leyes para la ciudad de México, así como en Coahuila, a la unión registrada se le solió catalogar como un contrato, a pesar de que, en ambas, sus exposiciones de motivos la sostenían en una unión familiar. ${ }^{15}$ El actual art. 291 Ter, califica al concubinato como parte de la familia.

\footnotetext{
${ }^{14}$ Leonel Pereznieto Castro, "Algunos aspectos del derecho familiar en México y otros países de Latinoamérica”, en Alfonso Luis Calvo Caravaca (comp.), El derecho de familia ante el siglo XXI: aspectos internacionales, Colex, Madrid, 2003, p. 20.

${ }^{15}$ Respecto a la ley de la Ciudad de México véase Adame Goddard, Jorge, "Análisis y juicio de la Ley de Sociedades de Convivencia para el Distrito Federal", en Boletín Mexicano de Derecho Comparado, núm. 120, 2007.
} 
El concubinato, como se acoge en México, es una parte del estado civil de las personas, aun cuando no exista un enunciado legal que expresamente así lo califique, aunque en algunas entidades federativas el registro Civil puede expedir constancias de declaración de constitución o terminación de concubinato. ${ }^{16} \mathrm{~A}$ pesar de lo parco que han sido los tribunales mexicanos sobre el particular, han dado por hecho que el concubinato es una institución propia del estado civil. ${ }^{17}$ Han seguido al efecto una regla de implicación lógica. Esto es, que se trata de una manera de ser, convivir y relacionarse, conformando el estatuto concubinario. Esta calificación nos lleva a afirmar que las relaciones entre los concubinos deben ser reguladas por la ley que regula el estado civil de las personas, incluida su disolución.

Vale tal calificación para los concubinatos registrados y los no registrados. Los dos, son a la vez de naturaleza concubinaria. No habría razón para decir que uno es un acto del estado civil y, el otro, un contrato.

\section{Regulación jurídica}

A falta de convenios internacionales y de prescripciones especiales de fuente interna, los problemas internacionales relacionados con el concubinato suelen ser regulados por normas conflictuales, que enseguida paso a presentar, sin olvidar el apoyo constitucional que se les ha dado en diversos lugares del mundo. ${ }^{18}$

${ }^{16}$ En la ciudad de México, a partir de 2014, es posible un registro de la unión concubinaria (arts. 291 Bis y ss. CCDF). Pero es necesario asentar que este "registro" solo vale como "declaración", pues el mismo Código expresa que: "las cuales (las constancias) sólo acreditan el hecho de la comparecencia y de haber emitido las declaraciones en ella contenidas".

${ }^{17}$ Acción de inconstitucionalidad 8/2014, registro: 2012590. Otro más es el que lleva como registro el 2012600. En sentido contrario afirmando que no crea un estado civil, el Tercer Tribunal Colegiado en Materia Civil del Primer Circuito, Sostuvo que no se trata de un estado civil, Registro: 173592.

Una propuesta para mejorar la regulación establecida en el CCDF respecto al concubinato puede verse en Fernando Barrera Zamorategui, "Hacia una mejor normatividad jurídica del concubinato en el Código Civil del Distrito Federal", en Estudios jurídicos que en homenaje a Antonio Ibarrola Aznar presenta el Colegio de Profesores de Derecho Civil de la UNAM, UNAM-Porrúa, México, 1996.

${ }^{18}$ Favio Esborraz explica que :"El reconocimiento de efectos jurídicos a la unión 
En principio, cabe tomar en cuenta el art. 13, fracc. I del CCFed, que prevé que las situaciones jurídicas creadas en el extranjero, se les aplicará el derecho del lugar de su constitución. Se trata de los llamados derechos adquiridos. En sentido similar, la Convención Interamericana sobre Normas Generales de Derecho Internacional Privado prescribe que:

Las situaciones jurídicas válidamente creadas en un Estado parte de acuerdo con las leyes con las cuales tenga una conexión al momento de su creación, serán reconocidas en los demás Estados Partes, siempre que no sean contrarias a los principios de su orden público (art. 7).

\section{a) Forma del acto constitutivo}

Debido a la naturaleza fáctica del concubinato tradicional no es posible advertir la forma de constitución, ${ }^{19}$ salvo en el caso del concubinato registrado. Esto nos lleva a tomar en cuenta la ley del lugar de la constitución del concubinato, para cualquiera de ambos tipos.

El CCFed establece que "la forma de los actos jurídicos se regirá por el derecho del lugar en que se celebren", a menos que se pacte u opte por otro orden jurídico (art. 13, fracc. IV. CCFed). Esto último, el pacto, sería posible en el caso de concubinatos registrados.

Ahora bien, en el caso de concubinatos no registrados, nada hay que se oponga para que en un concubinato tradicional los interesados puedan pactar el orden jurídico regulador. La autonomía de la voluntad lo permite; no existe prescripción que lo

convivencial comprende no solo lo que respecta a las relaciones personales y patrimoniales de la pareja, abarcando también todo lo concerniente a sus hijos naturales y/o adoptados, a quienes se reconocen -sin ningún tipo de discriminaciónlos mismos derechos que a los hijos concebidos dentro del matrimonio; garantizándoseles, además, que no se dejará constancia alguna de la naturaleza de la filiación en ningún documento oficial, así como tampoco del estado civil de los progenitores". Esborraz, David Flavio, "El concepto constitucional de familia en América Latina. Tendencias y proyecciones", en Revista de Derecho Privado. 2015, núm. 29, p. 36.

${ }^{19}$ Cierta parte de la doctrina alude a la existencia de actos sin forma. 
prohíba.

\section{b) Capacidad para constituir la relación concubinaria}

Se suele admitir que para constituir un concubinato se tiene capacidad cuando se tiene la misma establecida para celebrar nupcias (v.g., art. 2941 Código Civil de Jalisco). A la vez, que no concurra un impedimento, como los que se establecen para celebrar las nupcias ( $v$.g., parentesco en línea recta ascendente entre los sedicentes concubinos). Las leyes de varias entidades federativas suelen acoger la ley domiciliar o la lex fori.

Acorde a la norma de conflicto general, la capacidad de las personas físicas se regula conforme a la ley domiciliar (art. 13, fracc. II del CCFed).

Dentro de la capacidad se acogen al menos dos supuestos normativos que califican dentro de la capacidad: la edad y el consentimiento.

Edad. Algunos países establecen que la edad mínima para constituir el concubinato es de 18 años, otros, como Nueva Escocia, en Canadá, exigen 19; otros más, fijan la edad en 16, como en Gales. En México carecemos de disposición especial, pero por analogía se recurre a la prescrita para constituir el matrimonio.

Consentimiento. Para constituir el concubinato es necesario el consentimiento personal de cada uno, no admitiéndose el de un tercero. En algunos Estados se suele acoger la lex fori, en otros la ley del domicilio. Pero, aun en el caso de que en algún país extranjero fuese un tercero el que consienta, tal consentimiento no podría tomarse en cuenta en México, si con ello se vulneran derechos humanos, en especial la libertad de decidir.

\section{c) Relaciones concubinarias}

El efecto que produce la constitución de una relación concubinaria es lo que en doctrina también se conoce como relaciones concubinarias. En el ámbito jurídico corresponde a 
las disposiciones jurídicas que regulan las relaciones de la pareja. Estas, suelen referirse al mantenimiento reciproco entre los miembros que constituyen el concubinato, la posibilidad de adoptar a un menor como hijo, la fidelidad, la asistencia reproductiva, el apoyo y asistencia recíproca, etc.

La definición misma del concubinato, acarrea entre la pareja la obligación de cohabitar bajo el mismo techo, el débito carnal, el auxilio recíproco. La fidelidad, que algunos sostienen, otros la cuestionan, pues se dice que la infidelidad no puede ser sancionada, al no concurrir el adulterio. Otros, la admiten. El fundamento para sostener esta, Galván Rivera lo encuentra en la obligación de reparar el daño moral si uno de ellos fuese infiel, tal y como lo prescribe el Código civil. ${ }^{20}$

Este tipo de relaciones queda regulado por el orden jurídico que la norma de conflicto prevé para esos efectos. El CCFed (art. 13, frac. II), prescribe que el estado civil de las personas se regirá conforme al orden jurídico del lugar de su domicilio. Si tal domicilio se encuentra en México, tal será el orden jurídico que rija la situación. En la medida en que sus miembros cambien de domicilio, la regulación jurídica será tal.

La variación de la ley por cambio de domicilio es más dinámica que la establecida en países de la zona continental europea, que apelan a la ley de la nacionalidad, pues mientras la nacionalidad no cambie, la ley tampoco cambia, a pesar de que la pareja cambie de lugar y ambiente.

Claro está, que la pareja tiene la opción de elegir la ley reguladora de sus relaciones, a partir de la autonomía de la voluntad; al menos, en los concubinatos registrados.

\section{d) Efectos que produce la terminación del concubinato}

El concubinato, regularmente termina, por decisión propia entre los concubinos, en

${ }^{20}$ Galván Rivera, Flavio, opus cit. 
donde suele concurrir la autonomía de la voluntad para dar por concluidas sus relaciones, incluso, la voluntad unilateral. En México no es necesario la participación de alguna autoridad judicial, aunque tratándose de relaciones de pareja registradas, se suele exigir la participación de alguna autoridad. La omisión en precisar la terminación de las relaciones, puede ocasionar problemas internacionales, como adelante lo explico.

En algunos lugares suele prescribirse que uno de los concubinos debe de proporcionar una pensión alimenticia por un cierto periodo de tiempo, o alguna indemnización.

En el caso de fallecimiento de un miembro de la pareja, también se suele admitir el derecho a la sucesión mortis causae.

La regla reguladora de la terminación de las relaciones queda sujeta a la ley de la constitución, sin dejar de privar la autonomía de la voluntad.

La Conferencia de La Haya ha observado que la separación ha provocado algunos problemas conflictuales. Cita el siguiente caso, que he resumido:

Un belga se unió con un holandés mediante asociación registrada. La unión registró en Holanda. Seis años después, el belga abandonó a su pareja, regresó a Bélgica y se casó ahí con otro belga. Tiempo después, el holandés, se había quedado sin trabajo y demanda por alimentos a su pareja, que había huido.

En este caso, la relación no había quedado disuelta. Para la ley belga, la unión no era impedimento para celebrar nupcias con otra persona. Mientras que en Holanda era necesario que un tribunal disolviera la unión, eso no era necesario en Bélgica. Esto provocó una unión subsistente en Holanda y un matrimonio válido en Bélgica.

Para resolver este problema, sería recomendable que una unión registrada en el extranjero se mantenga como impedimento para celebrar nupcias, lo que no acontece en México. Cosa que podría ocurrir en algunas entidades federativas, no en todas. Las Notas de la Conferencia de La Haya concluyen explicando que: 
El Convenio de ICCS sobre el Reconocimiento de Asociaciones Registradas, que aún no ha sido firmado por los Estados, es el único instrumento internacional que regula directamente ciertos aspectos de las asociaciones registradas. Sin embargo, sólo es capaz de cubrir una pequeña parte de los problemas creados por la inconsistencia de los distintos sistemas jurídicos en relación con la asociación registrada, ya que se limita a los efectos del estatuto civil de las asociaciones. Otros efectos de la sociedad, como los efectos sobre los derechos de propiedad, no están dentro de su alcance. ${ }^{21}$

El problema no es fácil de resolver ni hay acuerdos unánimes entre los países. El 9 y 10 de marzo de 2017, se reunió la Academia de Derecho Europeo (Academy of European Law) en Tier, Alemania en la conferencia "Regímenes de propiedad de las parejas internacionales y el derecho de sucesión". Ahí participaron más de 60 académicos de 24 nacionalidades. Se presentaron diversas hipótesis. Se abordaron cuestiones relacionadas con el régimen de la propiedad, el divorcio (que también fue abordado), la sucesión y los alimentos, incluso la residencia habitual, la autonomía de la voluntad. Al final, no se llegó a un acuerdo unánime. Lo anterior significa que en estos temas la problemática subsiste y que los abogados deben tener cuidado al proporcionar consejos a sus clientes sobre la temática. ${ }^{22}$

\section{Reconocimiento del concubinato constituido en el extranjero}

En México no existe disposición que impida su reconocimiento de una unión concubinaria constituida en el extranjero, salvo que su constitución pugne con el orden público mexicano.

21 Note sur les developpements en droit interne et droit international prive sur la cohabitation hors mariage, y compris les partenariats enregistres, opus cit, notas 260 a 262. Hay otros ejemplos en esta obra, que conviene leer.

22 Tomado de la panorámica general resumida por Amandine Faucon, investigador del MPI de Luxemburgo. "Conference Report - Property regimes of international couples and the law of succession", en Conflict of laws.net, News and views in private international law, marzo 16, 2017. 
La Conferencia de La Haya ha observado problemas conflictuales relacionados con el reconocimiento. Cita el siguiente caso, que he resumido:

Dos belgas con asociación registrada en Bélgica, viajan a Moscú por carretera, pero en Minsk (Bielorrusia), uno de ellos quedó herido y fue llevado al hospital de ese lugar. El otro, que medio se ha incorporó de sus lesiones, acudió al hospital, pero se le negó acceso e información sobre su compañero, pues no estaba casado. En Bielorrusia no se reconoce la unión de pareja, ni siquiera la registrada, menos el derecho de cohabitación.

Como se observa, en el caso de mexicanos que viajen al extranjero, deben tomar en cuenta que su unión no necesariamente será reconocida. ${ }^{23}$

\section{Conclusión}

La carencia de regulación mexicana relacionada con los problemas de tráfico jurídico internacional relacionados con el concubinato, hace necesario fijarse metas y establecer reglas claras que incluyan su regulación. Pero para eso, es necesario que nuestros legisladores se pongan a trabajar y pensar en soluciones.

Aunque ciertamente es necesario tomar en cuenta diversos derechos humanos, ya reconocidos en forma general, también será necesario concretizar los datos o elementos reales a tomar en cuenta.

A mi parecer, es necesario comenzar enfatizando en la calificación de la situación, en la capacidad para constituir la unión, la forma (incluida la escrita y registrada), las

${ }^{23}$ Note sur les developpements en droit interne et droit international prive sur la cohabitation hors mariage, y compris les partenariats enregistres, opus cit, notas 269 a 271. 
relaciones de pareja (tomando en cuenta sus costumbres, a partir de la ley de la residencia habitual), así como los efectos de la terminación de la relación concubinaria.

En el ámbito convencional internacional es necesario contribuir para lograr un convenio sobre la materia, en el que se reconozcan los derechos, registros y efectos. 